

\section{DISCLAIMER}

This report was prepared as an account of work sponsored by an agency of the United States Government. Neither the United States Government nor any agency Thereof, nor any of their employees, makes any warranty, express or implied, or assumes any legal liability or responsibility for the accuracy, completeness, or usefulness of any information, apparatus, product, or process disclosed, or represents that its use would not infringe privately owned rights. Reference herein to any specific commercial product, process, or service by trade name, trademark, manufacturer, or otherwise does not necessarily constitute or imply its endorsement, recommendation, or favoring by the United States Government or any agency thereof. The views and opinions of authors expressed herein do not necessarily state or reflect those of the United States Government or any agency thereof. 


\section{DISCLAIMER}

Portions of this document may be illegible in electronic image products. Images are produced from the best available original document. 
Printed in the United States of America. Available from National Technical Information Service

U.S. Department of Commerce

5285 Port Royal Road, Springfield, Virginia 22161

Price: Printed Copy A02; Microfiche A01

This report was prepared as an account of work sponsored by an agency of the United States Government. Neither the United States Government nor any agency thereof, nor any of their employees, nor any of their contractors, subcontractors, or their employees, makes any warranty, express or implied, nor assumes any legal liability or responsibility for any third party's use or the results of such use of any information, apparatus, product or process disclosed in this report, nor represents that its use by such third party would not infringe privately owned rights. 
Date of Issue: September 25, 1979

Distribution Category: UC-38

\title{
DESIGN OF A POSITIONAL REFERENCE SYSTEM FOR ULTRAPRECISION MACHINING
}

\author{
J. B. Arnold \\ R. R. Burlesnn \\ R. M. Pardue
}

Fabrication Systems Department

Y-12 Development Division

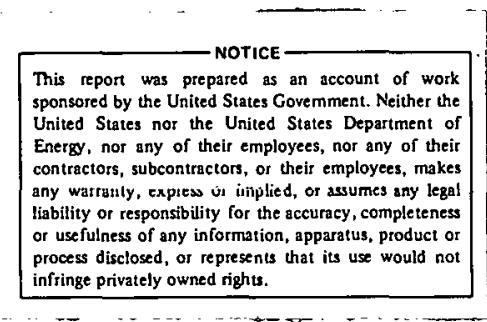

Oak Ridge $Y-12$ Plant

P. O. Box Y, Oak Ridge, Tennessee 37830

Prepared for the Department of Energy Under US Government Contract W-7405-eng-26 


\section{- ABSTRACT}

The primary goal for an ultraprecision turning machine is to have the capability to position precisely the cutting points of a tool along a defined contour with respect to the part. In order to accomplish this goal, the use of a stable-positional-reference system has become apparent. Several efforts have been made by representatives of the diamond-turning community to design such a needed reference system. This report reviews efforts made at $\mathrm{Y}-12$ to design the needed system. 


\section{CONTENTS}

INTRODUCTION ...................................... 4

Future Work $\ldots \ldots \ldots \ldots \ldots \ldots \ldots \ldots \ldots \ldots \ldots \ldots \ldots, 4$

A POSITIONAL REFERENCE SYSTEM FOR ULTRAPRECISION

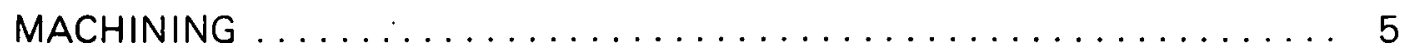

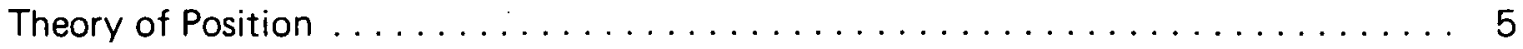

Reference System ..................................... 7

Metering Bar Assembly ............................ 7

Tool Post ................................. 7

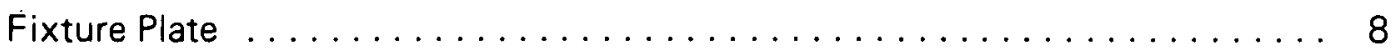

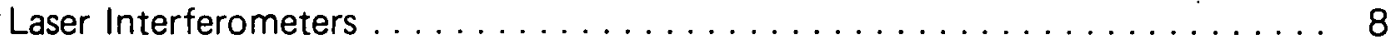

Control ........................................... 10

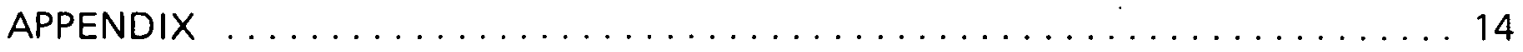

Machine Movement Equations ................................ 14

Tool Motion .................................... 14

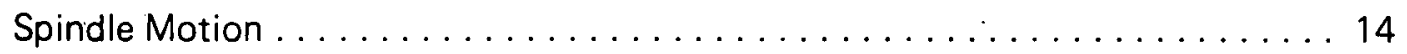

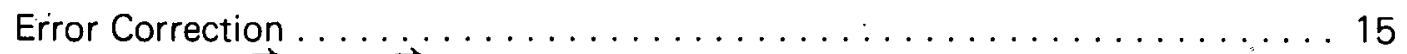

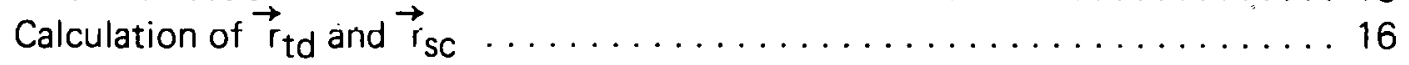




\section{INTRODUCTION}

As the quality requirements on metal optics become more demanding so do the performance requirements on the machines that produce these optics. At the Oak Ridge Y-12 Plant(a) a continuing program in the development and study of ultraprecision machine-tool performance has been conducted for more than sixteen years. During this time, a substantial effort has been directed to the development of a single-point, optical, machining process. This process incorporates a high-quality-edged single-crystal diamond tool and an ultraprecision multiaxis turning machine. Recently developed machines have employed laser interferometer feedback, which aids in determining the slides' positions relative to reference points on the machine base and the slideway base. Because of rotation (amplified by Abbé offset) and strain (resulting from heat and forces), the relative motions between the tool and the reference points on the slides have been considerable. The same is true for relative motions between the part and the reference points on the machine base. For these reasons, the present precision turning machine cannot produce parts to the needed tolerances. To provide cybernetics for precisely positioning the tool with the part, a position reference system is being developed.

\section{FUTURE WORK}

Efforts to convert the concepts reviewed in this report into workable hardware are being made at the $\mathrm{Y}-12$ Plant. The work will include design, fabrication, and testing. The design and fabrication of all reference-system components are estimated to be complete by April 1 , 1980; while testing the system is estimated to be complete July 1, 1980.

(a) Operated by the Union Carbide Corporation's Nuclear Division for the Department of Energy. 


\section{A POSITIONAL REFERENCE SYSTEM FOR ULTRAPRECISION MACHINING}

\section{THEORY OF POSITION}

The position of a point can be defined only within the framework of an established reference system. Definition of distance and direction is required to define the point position. The position of Point $A$, for example, in Figure 1 is defined as $X_{A}, Y_{A}$; and the position of Point $B$ is defined as $X_{B}, Y_{B}$.

In Figure 2 it may be noted that the relative distance between Point $A$ and Point $B$ is not affected when the reference system ( $X-Y$ axes) shifts. The reference system may translate and/or rotate without affecting the relative distance from $A$ to $B$. It is expressed mathematically as

$$
\sqrt{\left(X_{A}-X_{B}\right)^{2}+\left(Y_{A}-Y_{B}\right)^{2}}=\sqrt{\left(X_{A}^{\prime}-X_{B}^{\prime}\right)^{2}+\left(Y_{A}^{\prime}-Y_{B}^{\prime}\right)^{2}}
$$

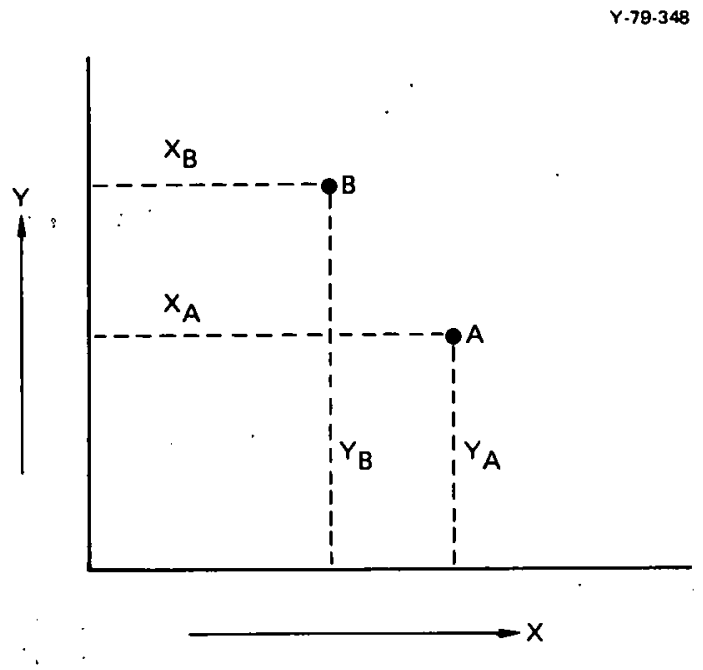

Figure 1. THE POSITION OF POINT A IS DEFINED AS $X_{A}, Y_{A}$; THE POSITION OF POINT $B$ IS DEFINED AS $X_{B}, Y_{B}$.

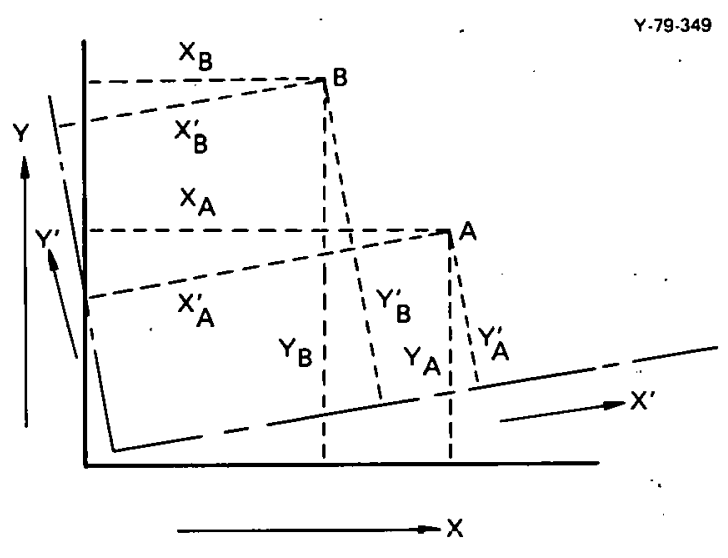

Figure 2. A TRANSLATION AND/OR ROTATION OF THE REFERENCE SYSTEM ON THE X-Y PLANE DOES NOT AFFECT THE DISTANCE BETWEEN POINTS A AND B.

With proper setup and arrangement, laser interferometers may be used to determine the $X$ and $Y$ displacement of Points $A$ and $B$; and, as long as the angular rotation of the reference system is small and there is no angular change between the $X$ and $Y$ axes, the relative displacement of $A$ and $B$ can also be determined. It should be noted that the angle between the $X$ and $Y$ axes is not required to be a perfect 90-degree angle but only required to be known and to remain fixed during use. This positional concept is being incorporated in a recently conceived reference system for ultraprecision machining. If Point $A$ is a point on the part to be machined and Point $B$ is a point on the tool, then (with proper controls and a stable reference system) the distance between $A$ and $B$ can be made to equal zero.

The parts to be machined are not single points, but consist of contoured surfaces which are loci in the cutting plane. A description of the position of a locus is more complex than a description of the position of a point. 
Locus-position description requires that the location of two specific points on the locus be identified. This is done by determining the $X$ and $Y$ positions of two points as shown in Figure 3. The dotted lines in this figure represent known distances, and it can be seen that four distances must be known to specify the position of the locus. In Figure 4 only three distances must be known when two, aligned in the same direction, are spaced a known

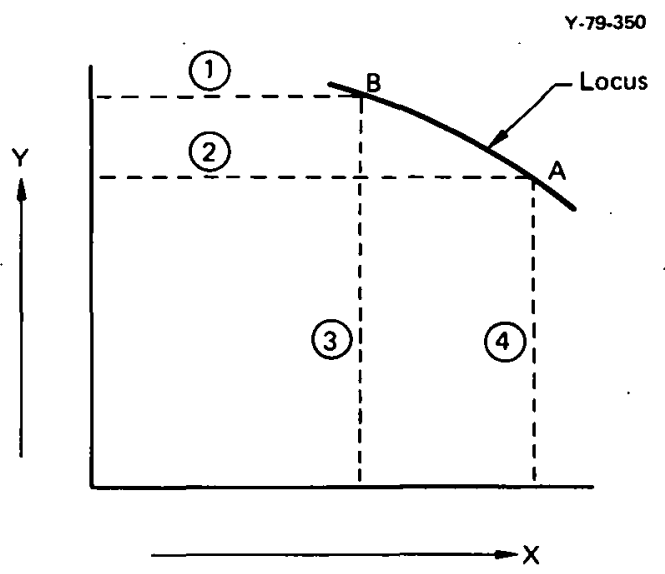

Figure 3. TO DETERMINE THE POSITION OF THE LOCUS, THE POSITION OF TWO SPECIFIC POINTS MUST BE DEFINED.

distance, $F$. This is an important concept for it reduces the number of lasers and interferometers needed to monitor positions in the ultraprecision. machining process.

Neither is the tool a single point; it is a locus also. As in part positioning, it is necessary that the tool position also be determined with three reference dimensions. The points along each locus cannot be measured directly; therefore, reference points were selected that connected rigidly to the tool and the part.

Figure 5 shows the arrangement of the reference system that was designed for

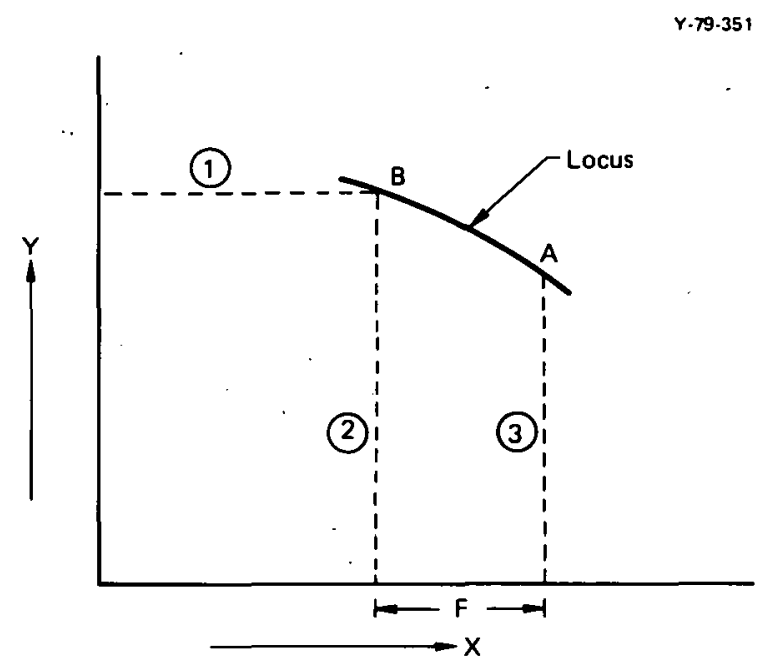

Figure 4. THE POSITION OF A LOCUS DEFINED WITH THREE DIMENSIONS IF TWO ARE ALIGNED AT A KNOWN DISTANCE, F.
Note: F Distances are known and fixed.

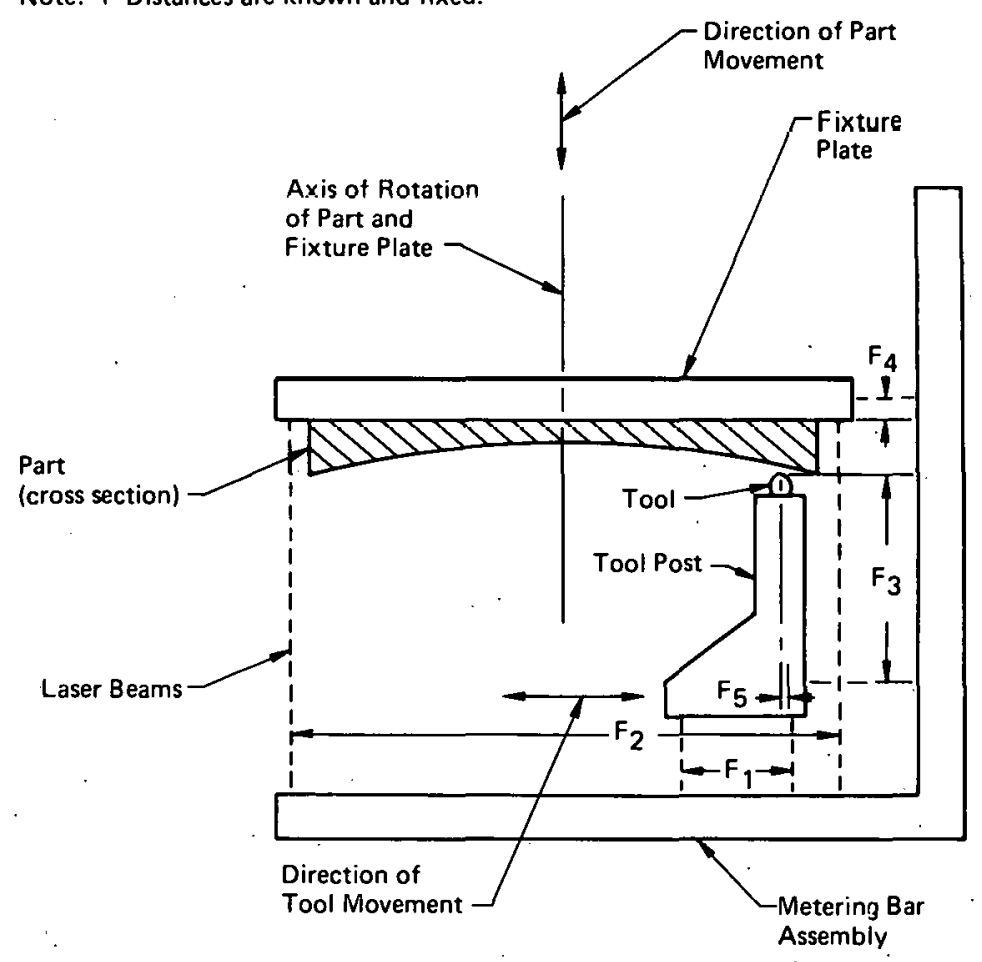

Figure 5. THE REFERENCE SYSTEM. 
determining the tool-to-part relationship. The reference positions on the part and the tool were selected to minimize both Abbé-offset effects and the distance between the reference points and the points of interest (on the part and on the tool) while providing machining flexibility for the various contours. Experience has confirmed that when the reference points are significantly removed from the points of interest, the positional determinations of these interest points are impaired. The degrees of strain (resulting from heat and forces) between reference points and points of interest on the loci are related linearly to the distance between the points, the properties of the materials, and the properties of the connections between the points. Consequently, it is essential that a thermally stable and rigid material be used in the construction of the tool post and fixture plate.

With real-time position control, a correct tool-geometry definition, and a properly defined stable reference system, it will be possible to position the cutting points of a tool along a defined part locus with a greater degree of accuracy than has been attained previously. Work is in progress to design and fabricate the hardware needed to apply the positional-reference concepts to the POMA machine.

\section{REFERENCE SYSTEM}

The reference system consists of five major components, (1) a metering bar assembly, (2) a tool post, (3) a fixture plate, (4) laser interferometers, and (5) controls. Each component is vital to the performance of the system, and each must perform to demanding specifications.

\section{Metering Bar Assembly}

The metering bar assembly is to be comprised of two, high-quality optical flats defined as a longitudinal bar and a transverse bar. The bars are to be fabricated from a thermally stable ceramic (glass) and are to be assembled using Invar bolts for rigidity. The bar assembly will form a 90-degree reference system with a longitudinal leg 1.75-m (69-in) long. The reference surface on each bar is to be of high optical quality with a pitch-polish finish $>80 / 50$ scratch/dig ratio and an overall peak-to-valley figure quality $>0.5 \mathrm{ppm}$ (with slope errors not to exceed $1 \mu \mathrm{in} / \mathrm{in}$ ). Extremely high figure quality is not required since the slope errors will be predetermined and compensation made during machining operations.

The bar assembly is to be supported by three brackets fastened to the machine base. A three-ball support technique will be used between the brackets and the assembly to minimize forces which might otherwise be transmitted through the support brackets.

\section{Tool Post}

The tool post will support the tool rigidly in coordination with three reference mirrors. The distance between the reference mirrors and the cutting points on the tool must be determined accurately so that the position of the cutting point may be monitored with three laser interferometers. The tool post is to be in position on the $X$ slide of the machine 
with its principal motion in the transverse direction. The selected tool positionrelative to the reference mirrors-was based on metrology principles (as was reviewed in the section, Theory of Position) while allowing machine flexibility for parts production. The tool post will enable the machine to produce parts ranging from the large, relatively shallow ones as depicted in Figure 5 to the large, cylindrical contours shown in Figure 6.

Present plans are to construct the tool-post base from a stable cast iron and to use a $63.5-\mathrm{mm}$ (2.5-in)-diameter, tungsten-carbide boring bar to fix the tool to the base. Three reference mirrors are to be fastened rigidly to the tool-post base. This base will be supported on the $X$ table using the three-ball support technique, which will minimize the transfer of changing forces from the $X$-table to the tool-post base.

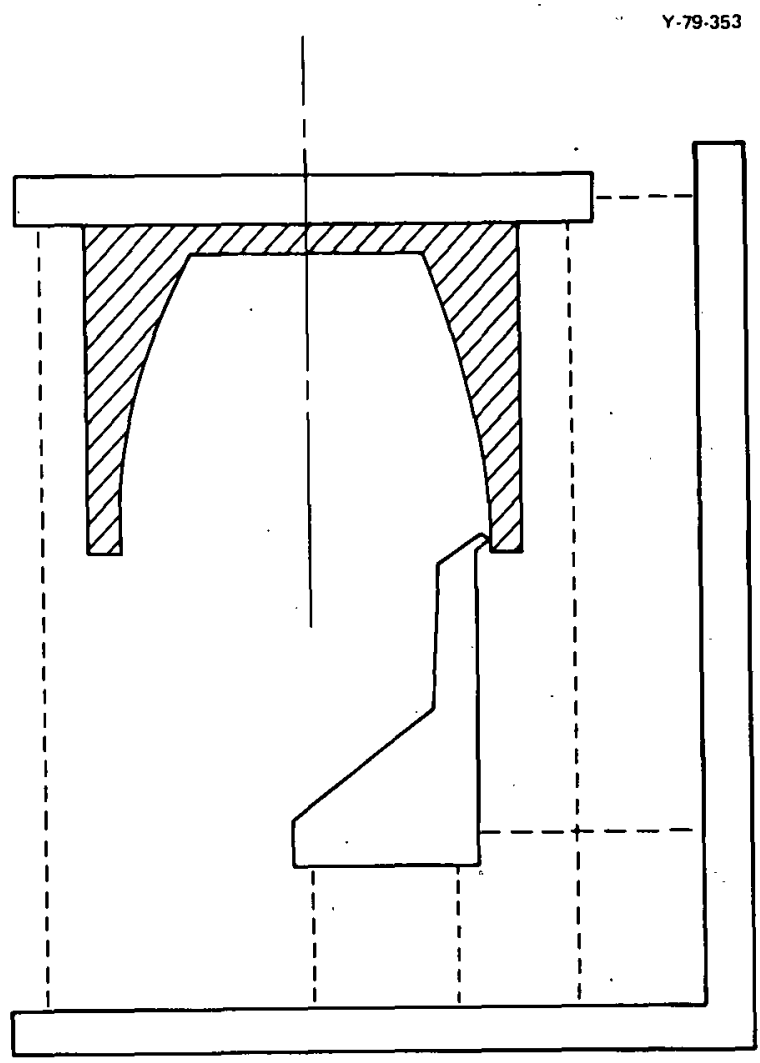

Figure 6. THE REFERENCE SYSTEM WILL ALLOW THE MACHINING OF LARGE, CYLINDRICAL PARTS.

\section{Fixture Plate}

Like the tool post, the fixture plate will be an inflexible structure with three reference mirrors. It will be fabricated to support rigidly a variety of parts by using a vacuum, a pot-fixturing technique, or by bolting. The reference surfaces on the fixture plate will be coated with a durable, diamond-machinable material such as electroless-plated nickel in order that the required reference surfaces may be produced on the lathe.

\section{Laser Interferometers}

Laser interferometers are to be the position-sensing elements of the system. Three lasers will be used with six special interferometers to determine the positional relationship of the fixture plate and the tool post. The special interferometers are referred to as dual-surface (double-pass) interferometers. A sketch is shown in Figure 7. The term, double pass, refers to the number of times that the beam strikes each surface of interest. By double passing the beam, the resolution of the system is enhanced by a factor of two. The interferometer will determine the relative movement between two flat mirrors in the direction of the beam. To allow use of interferometers in determining the relative movement of the cylindrical section of the fixture plate, a cylindrical lens will be employed. A cylindrical lens will focus the laser beam to the center of the fixture plate, and thereby allow the diameter of the fixture plate to change without requiring relocation of the lens. Artist concepts depicting the 
arrangements of the lasers and interferometers are seen in Figures 8 and 9 . This laser-interferometer arrangement provides a means of maintaining the part-to-tool position relationship.

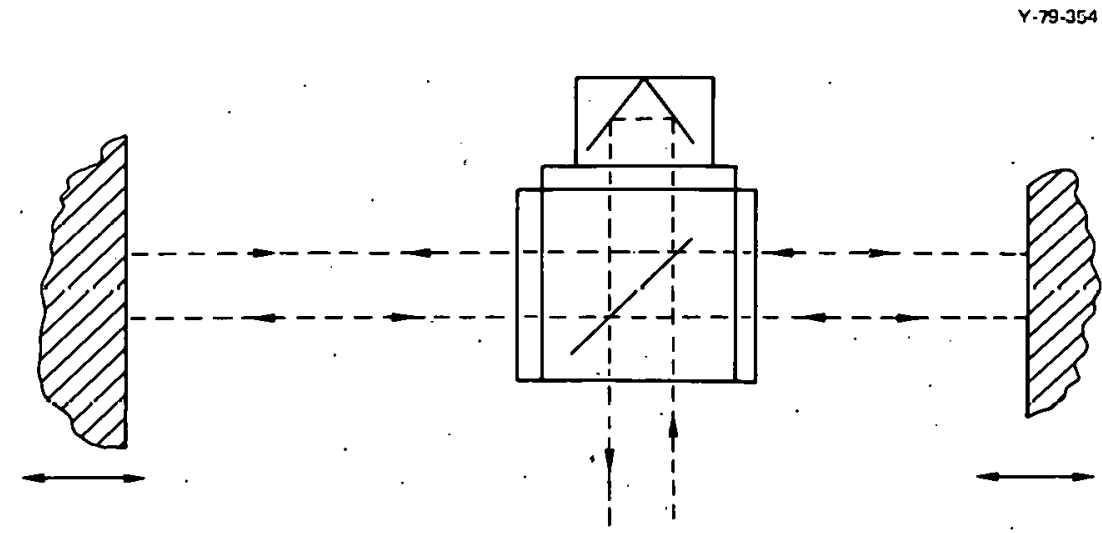

Figure 7. DUAL-SURFACE (DOUBLE-PASS) INTERFEROMETERS ENHANCE THE RESOLUTION OF THE SYSTEM BY A FACTOR OF TWO.

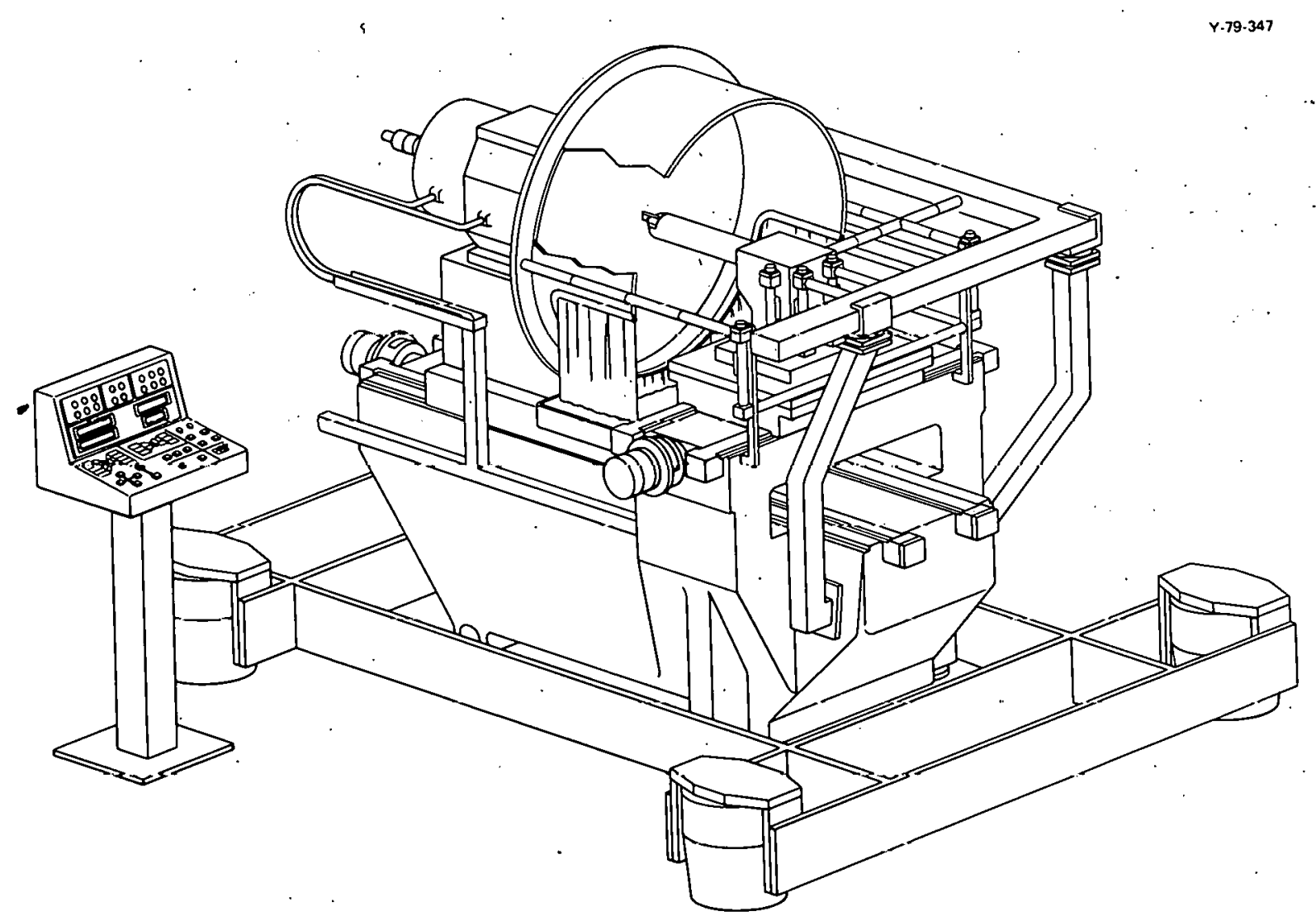

FiguiE 8. LAGER-INTERFEROMETER ARRANGEMENT. 


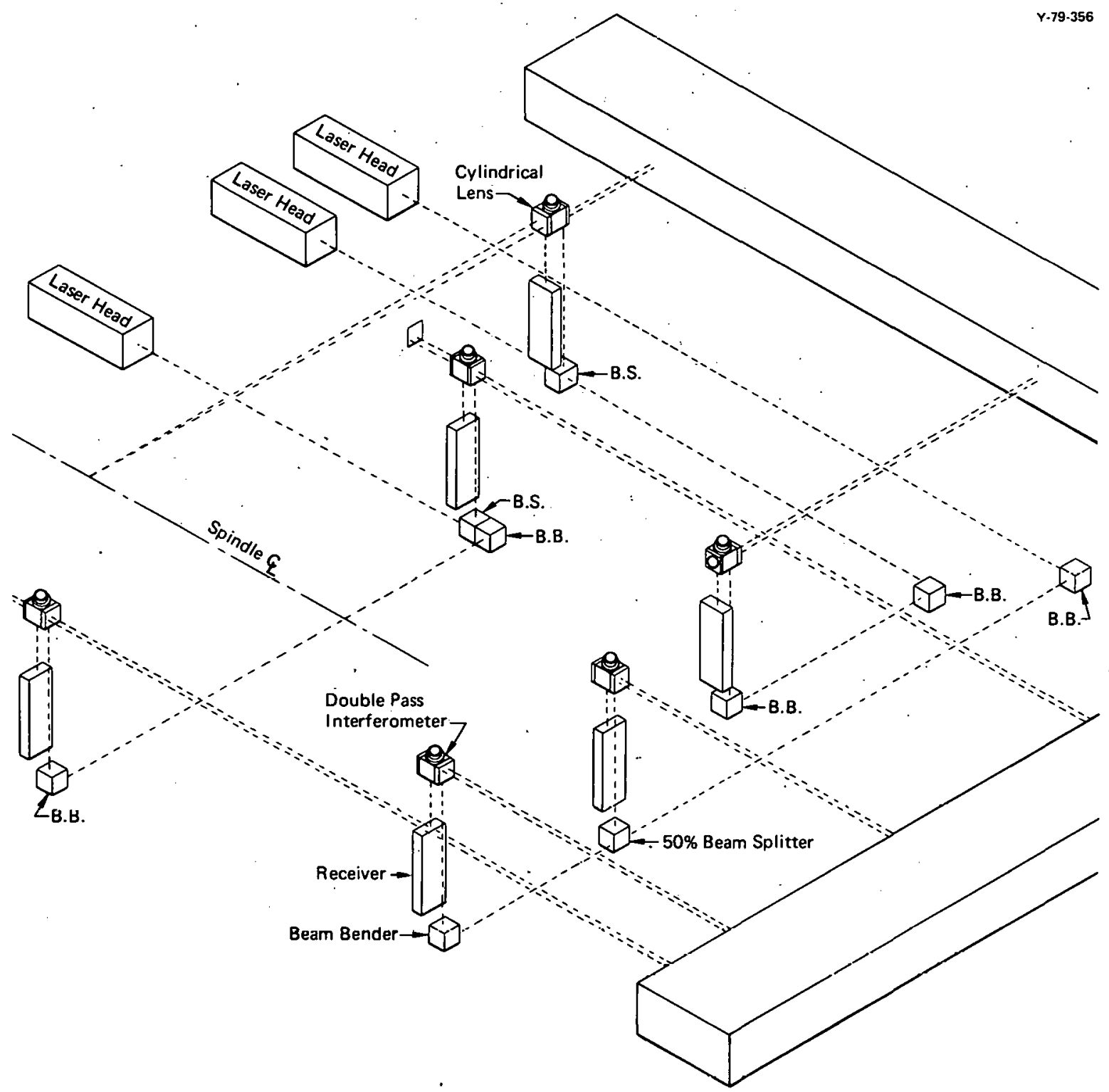

Figure 9. THREE LASERS WITH SIX DUAL-SURFACE (DOUBLE-PASS) INTERFEROMETERS.

\section{CONTROL}

The theory for the positioning system described is based on calculations to find the actual position of the tool relative to the programmed position of the tool on the part. Equations are developed for these calculations in the Appendix of this report and are rewritten in a somewhat different form, as follows:

$$
e_{x}=\left(u_{6}-u_{5}\right)+\left(v_{1}-v_{2}\right)\left(\frac{x_{s c}}{I_{1,2}}\right)-\left(v_{3}-v_{4}\right)\left(\frac{y_{t d}}{I_{3,4}}\right)-x_{p}
$$




$$
e_{y}=\frac{1}{2}\left(v_{1}+v_{2}\right)-\frac{1}{2}\left(v_{3}+v_{4}\right)+\left(v_{1}-v_{2}\right)\left(\frac{x_{S c}}{I_{1,2}}\right)-\left(v_{3}-v_{4}\right)\left(\frac{y_{t d}}{I_{3,4}}\right)-Y_{p}
$$

If a maximum error of $25 \mathrm{~nm}(1 \mu \mathrm{in})$ could be tolerated and the machine were allowed to run at $5 \mathrm{~mm} / \mathrm{min}(0.2 \mathrm{in} / \mathrm{min})$ then the update rate would be:

$$
R=5\left(\frac{\mathrm{mm}}{\min }\right)\left(\frac{1}{60} \frac{\mathrm{min}}{\mathrm{sec}}\right)\left(\frac{1}{25 \times 10^{-9}} \frac{\text { pulse }}{\mathrm{nm}}\right)=3.3 \mathrm{kHz} .
$$

This implies that the correction system must perform the necessary calculations and output a new error every $300 \mu \mathrm{sec}$ to maintain a $25-\mathrm{nm}(1-\mu \mathrm{in})$-error bound. Based upon the complexity of the equations and the requirements for extreme accuracy, a bit-slice microprocessor was selected. A block diagram is provided in Figure 10. All variables and constants will be read into the microprocessor and converted to a base of $6 \mathrm{~nm}(0.25 \mu \mathrm{in})$. This base was selected because it is the resolution of the laser and the positioning system.

The variables $v_{1}-v_{4}$ and $u_{5}-u_{6}$ represent the actual position of specific points on the machine. These variables are obtained from the laser-interferometer system and stored in UP/DOWN counters. The numbers stored (in the counters) have a base of $\lambda / 120$, where $\lambda$ is the wavelength of helium-neon ( $\mathrm{He}-\mathrm{Ne}$ ). Since the speed of light is not constant in air (in fact, it varies with air temperature, air pressure, and humidity), a compensation for this is performed. An auxiliary microprocessor calculates the compensated wavelength, $\lambda_{c}$, from the environmental conditions and supplies that information to the master microprocessor. The compensated wavelength is then used to convert $\lambda$ to a base of $6 \mathrm{~nm}(0.25 \mu \mathrm{in})$.

The variables $X_{p}$ and $Y_{p}$ represent the program position of each machine axis. These variables are obtained from the control unit interpolators and stored in UP/DOWN counters. The variables $x_{S C}$ and $y_{S C}$ represent the $x$ and $y$ components of the program displacement of the tool relative to the centerline of the spindle. These variables are loaded into a DOWN counter by the control unit. The interpolators are used to decrement the counters; as a result, the actual value of $x_{S C}$ and $y_{S C}$ is available to the microprocessor at all times.

The constants $I_{1,2}$ and $I_{3,4}$ are entered into an auxiliary microprocessor through a cathode-ray-tube (CRT) terminal. This microprocessor converts the constants to the appropriate base and provides them to the master microprocessor upon request. The variables $x_{t d}$ and $y_{t d}$ are the $x$ and $y$ components of the distance from the center of the tool post to the position of the tool that contacts the part. These variables are formed by the auxiliary microprocessor from the tool-contour data inputed to the CRT terminal. These values are updated every 0.1 degree of movement on the tool as defined by the master microprocessor.

The variables $x_{d}$ and $y_{d}$ represent the position of the machine slides as defined by the laser-interferometer system. 


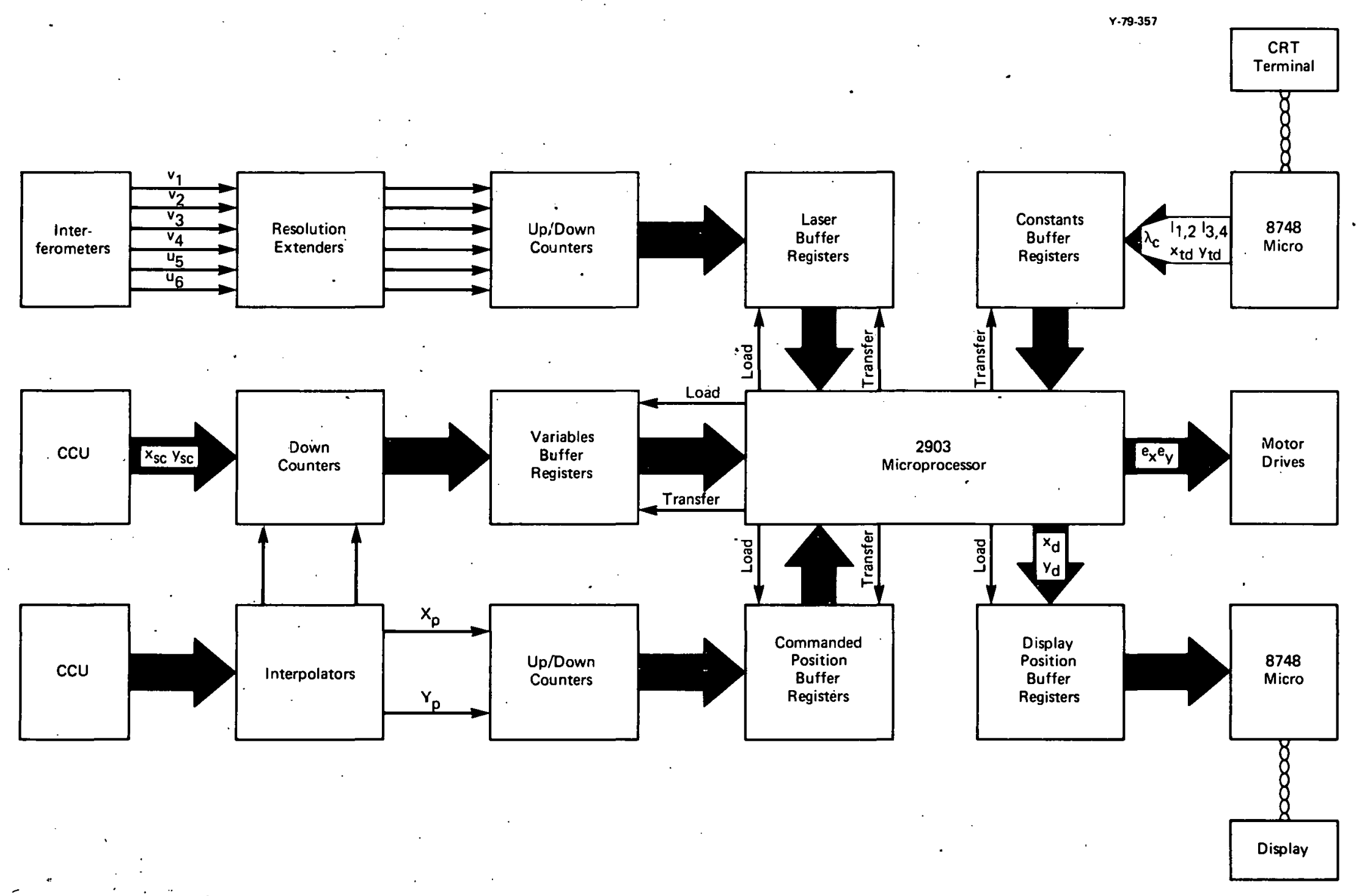

Figure 10. CORRECTION-SYSTEM BLOCK DIAGRAM. 


$$
\begin{aligned}
& x_{d}=u_{5}-u_{6} \\
& y_{d}=\frac{1}{2}\left(v_{1}+v_{2}\right)-\frac{1}{2}\left(v_{3}+v_{4}\right)
\end{aligned}
$$

These variables are converted from the base $6 \mathrm{~nm}(0.25 \mu \mathrm{in})$ to binary-coded decimal (BCD) by an auxiliary microprocessor and sent to the position displays. The position-error values $e_{x}$ and $e_{y}$ are sent to the motor drive system. These values are used by the drive system as a measure of velocity; the larger the error, the faster the motors run.

The software programs for use with this system are for preprocessing and control. The preprocessing is accomplished on a large computer system; its function is to correct the part tape for the lack of straightness in the reference flats and the contour errors of the tool. This information is then used by the control unit interpolators to form the program position $X_{p}$ and $Y_{p}$ information. The control software is run on the master microprocessor. It reads in all variables and constants from their buffers and converts them to a base of $6 \mathrm{~nm}$ $(0.25 \mu \mathrm{in})$. Also performed is the conversion of the laser-interferometer data from wavelength to inches. The displayed distances $x_{d}$ and $y_{d}$ are calculated and output to the auxiliary microprocessor. The final action is to calculate the error components $\left(e_{x}\right.$ and $\left.e_{y}\right)$ and to output them to the motor drives after appropriate scaling. This control software runs continuously and cycles through a sequence in $<150 \mu \mathrm{sec}$; hence, the entire system is allowed to operate at a $13 \mathrm{kHz}$ bandwidth. This value will keep the system error $<25 \mathrm{~nm}$ $(1.0 \mu \mathrm{in})$. 


\section{APPENDIX}

\section{MACHINE MOVEMENT EQUATIONS}

\section{Tool Motion}

Assuming the tool post is rigid, let $\vec{r}_{\text {td }}$ be the position vector from Point $t$ to Point $d$ in Figures $A-1$ and $A-2$. In terms of units vector $\hat{i}$, and $\hat{j}$

$$
\vec{r}_{t d}=x_{t d} \hat{i}+y_{t d} \hat{j}
$$

Define the Point $t$ to be the midpoint between the intersection of Beam Paths 3 and 6 and the intersection of Beam Paths 4 and 6. The displacement of Point $t$, in terms of measured displacements $(3,4$, and 6 relative to the reference system) is given by

$$
\vec{\delta}_{t}=u_{t} \hat{i}+v_{t} \hat{j}=u_{6} \hat{i}+\frac{v_{3}+v_{4}}{2} \hat{j}
$$

where $v_{3}$ is the measured displacement from laser Beam 3 and away is + .

Then, using $\vec{r}_{t d}$, the displacement of Point $d$ is given by ( $x$ indicates the vector cross product)

$$
\vec{\delta}_{\mathrm{d}}=\vec{\delta}_{\mathrm{t}}+\vec{w}_{\mathrm{t}} \times \vec{r}_{\mathrm{td}}
$$

where $\vec{w}_{t}$ is the angular displacement of vector $\vec{r}_{t d}$. Since the post is assumed rigid, define $\vec{w}_{\mathrm{t}}$ to be

$$
\vec{w}_{t}=w_{t} \hat{k}, w_{t}=\frac{v_{3}-v_{4}}{I_{3,4}}
$$

Note that $\hat{i}$ and $\hat{j}$ components are neglected.

Equations 1, 2, and 3 may be combined to obtain

$$
\vec{\delta}_{d}=\left(u_{t}-w_{t} v_{t d}\right) \hat{i}+\left(v_{t}+w_{t} x_{t d}\right) \hat{j}
$$

\section{Spindle Motion}

Similarly, define a Point $s$ on the spindle such that $s$ is the midpoint between the intersection of Beam Paths 5 and 1 and the intersection of Beam Paths 5 and 2 in Figure A-3. An additional constraint will be that $s$ will lie on the spindle centerline so that the equation of the surface contour can be used to define $\vec{r}_{\text {SC }}$ easily. Thus 


$$
\vec{r}_{s c}=x_{S C} \hat{i}+y_{s c} \hat{j}
$$

Let

$$
\vec{\delta}_{s}=u_{s} \hat{i}+v_{s} \hat{j}
$$

From the above definitions,

$$
\begin{aligned}
& u_{s}=u_{5} \\
& v_{s}=\frac{v_{1}+v_{2}}{2} .
\end{aligned}
$$

Now the motion of Point $c$ can be expressed as

$$
\vec{\delta}_{C}=\vec{\delta}_{S}+\vec{w}_{S} \times \vec{r}_{S C}
$$

where

$$
\begin{aligned}
& \vec{w}_{s}=w_{s} \hat{k} \\
& w_{s}=\frac{v_{1}-v_{2}}{I_{1,2}}
\end{aligned}
$$

is the angular displacement of the spindle.

Using Equations 7 and 10, obtains

$$
\vec{\delta}_{c}=\left(u_{s}-w_{s} y_{s c}\right) \hat{i}+\left(v_{s}+w_{s} x_{s c}\right) \hat{j}
$$

\section{Error Correction}

The program motion of the two slides in the basic reference system is

$$
\begin{aligned}
& \vec{\delta}_{s}^{\prime}=Y_{p} \hat{j} \text {.spindle slide and } \\
& \vec{\delta}_{t}^{\prime}=x_{p} \hat{i} \text { tool slide }
\end{aligned}
$$

where $X_{p}$ and $Y_{p}$ are the program $X$ and $Y$ positions. Since the program positions and the true positions of Points $c$ and d differ, define the $X$ and $Y$ errors to be 


$$
\begin{aligned}
& e_{x}=\delta_{d x}-\delta_{c x}-X_{p} \\
& e_{y}=\delta_{c y}-\delta_{d y}-Y_{p} .
\end{aligned}
$$

Using Equations 5, 13, 16, and 17, arrive at

$$
\begin{aligned}
& e_{x}=\left(u_{t}-w_{t} y_{t d}\right)-\left(u_{s}-w_{s} y_{s c}\right)-x_{p} \\
& e_{y}=\left(v_{s}+w_{s} x_{s c}\right)-\left(v_{t}+w_{t} x_{t d}\right)-Y_{p} .
\end{aligned}
$$

\section{Calculation of $\vec{r}_{\text {td }}$ and $\vec{r}_{\text {sc }}$}

Since Point $c$ on the part changes position with respect to Point $s$ on the spindle as the cut progresses, the radius vector $\vec{r}_{\mathrm{SC}}$ will change. Also, since Point $d$ on the tool changes during a cut, the vector $\vec{r}_{\text {td }}$ will change. Let $\vec{r}_{\text {td }}$ be given by

$$
\vec{r}_{\mathrm{td}}=\vec{r}_{\mathrm{td}}+\Delta \vec{r}_{\mathrm{td}}
$$

where $\vec{r}_{t_{0}}$ is the position at some starting point on the tool $\left(d_{0}\right)$ and $\Delta \vec{r}_{t d}$ is the change in position on the tool relative to Point $t$ (see Figure A-4). Thus $x_{t d}$ and $y_{t d}$ in Equation 1 are given by

$$
\begin{aligned}
& x_{t d}=x_{t d_{0}}+\Delta x_{t d} \\
& y_{t d}=y_{t d_{0}}+\Delta y_{t d}
\end{aligned}
$$

Similarly define $\vec{r}_{\$ C}$ to be

$$
\vec{r}_{\mathrm{SC}}=\vec{r}_{\mathrm{SC}_{\mathrm{O}}}+\Delta \overrightarrow{\mathrm{r}}_{\mathrm{SC}}
$$

where $\vec{r}_{\mathrm{SCO}}$ is the position of Point $c$ at some starting point, $\mathrm{c}_{\mathrm{O}}$, and $\Delta \overrightarrow{\mathrm{r}}_{\mathrm{SC}}$ is the change in position of $c$ relative to Point $s$ in Figure A-5.

Given that Point $c_{o}$ and $d_{o}$ coincide at the start of the machining process, then $\overrightarrow{\Delta r} d t$ and $\Delta \vec{r}_{\text {SC }}$ are related by

$$
\begin{aligned}
& \Delta x_{s c}=\Delta x_{p}+\Delta x_{t d} \\
& \Delta y_{s c}=-\Delta y_{p}+\Delta y_{t d} .
\end{aligned}
$$

Since errors in $\Delta x_{t d}$ and $\Delta y_{t d}$ lead to second-order effects, it should be possible to calculate them prior to machining and to ignore contributions from slide straightness and yaw. 


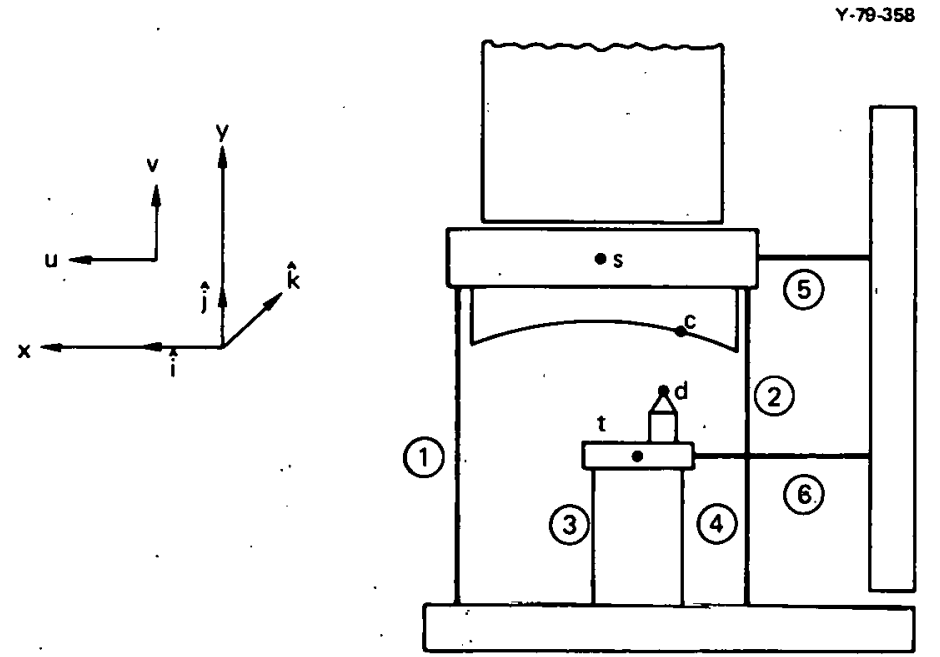

Figure A-1. PART-TO-TOOL RELATIONSHIP.

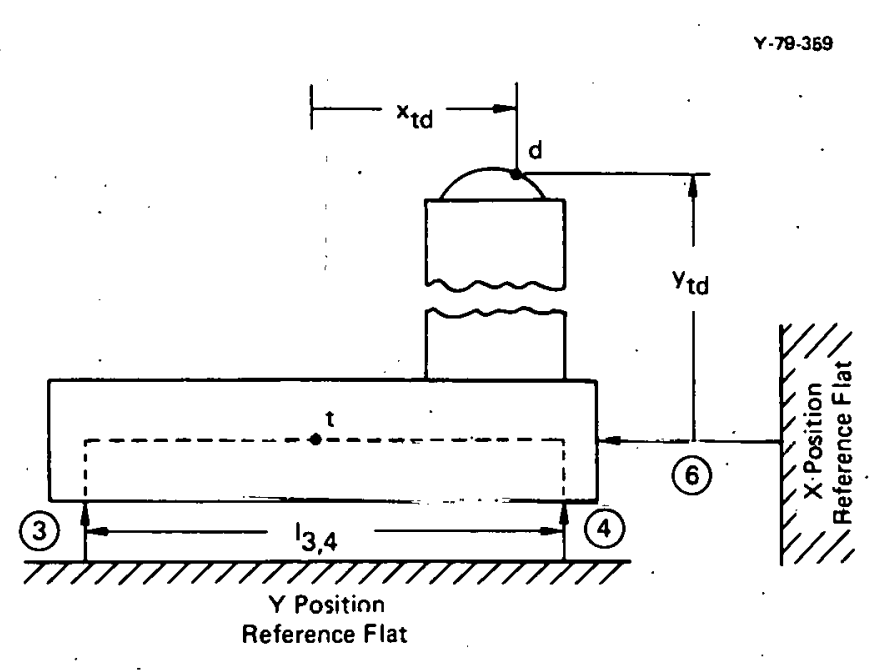

Figure A-2. TOOL-TO-REFERENCE RELATIONSHIP.

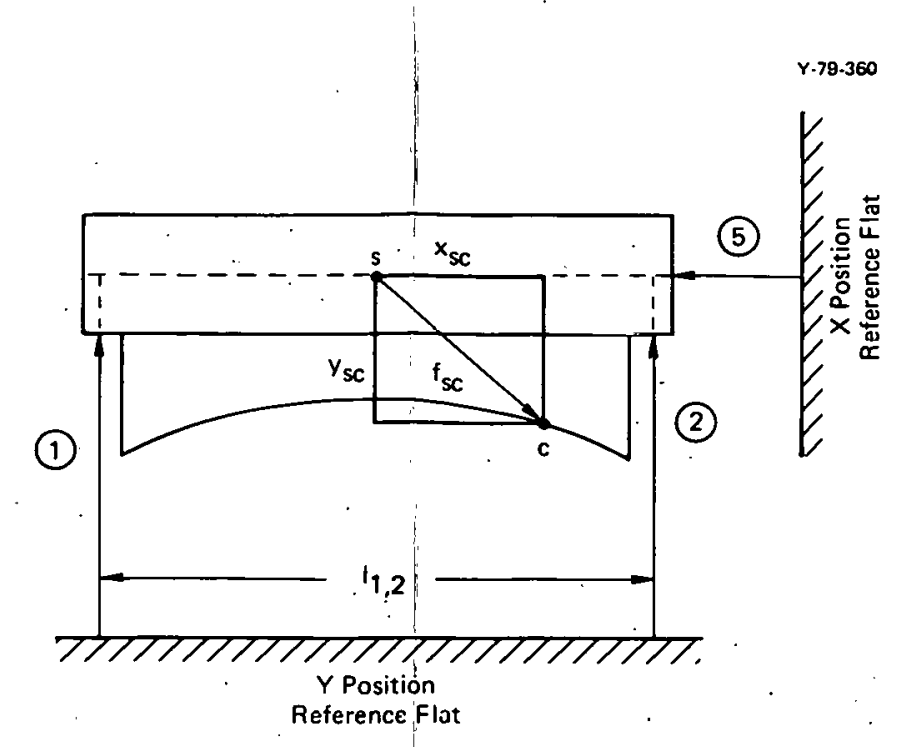

Figure A-3. PART-TO-REFERENCE RELATIONSHIP.

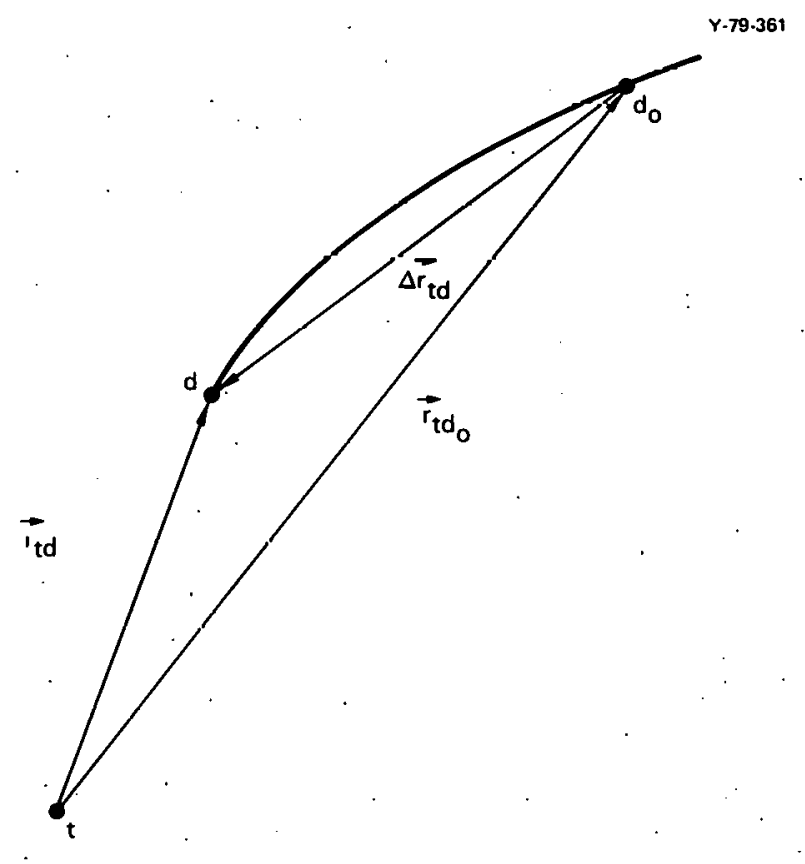

Figure A-4. TOOL POINT AND VECTOR CHANGE DURING A CUT.

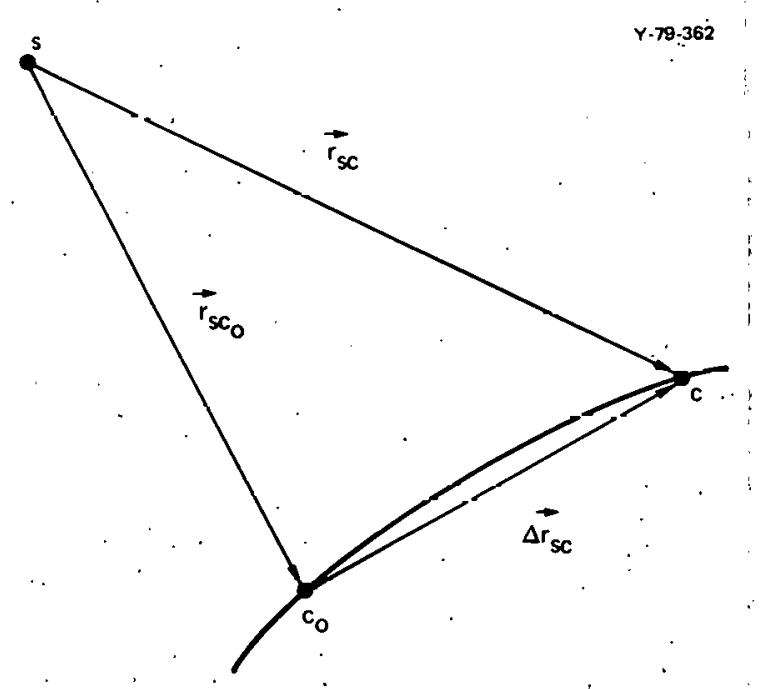

Figure A-5. PART AND VECTOR CHANGE DURING A CUT. 


\section{Distribution}

Department of Energy - Oak Ridge

Hickman, H. D.

Leed, R. E.

Poteat, R. M.

\section{Lawrence Livermore Laboratory}

Arnold, W. F.

Bryan, J. B.

Donaldson, R. R.

Thompson, D. C.

Los Alamos Scientific Laboratory

Hoyt, H. C.

Naval Weapons Center - China Lake

Decker, D.

Oak Ridge Gaseous Diffusion Plant

Armstrong, R. C.

Stief, S. S.

Wilcox, W: J., Jr

\section{Oak Ridge National Laboratory}

Hopkins, C. C.

\section{Oak Ridge $Y-12$ Plant}

Arnold, J. B.

Bender, F. U.

Burditt, R. B.

Burleson, R. R. (5)

Dodson, W. H./Googin, J. M.

Fraser, R. J.

Gerth, H. L.

Jones, F.W.

Keith, A.

Kite, H. T.

Marcum, R. C.

Mills, J. M., Jr

Pardue, R. M.

Phillips, L. R.

Preuss, H. M.

Steger, P. J.

Thompson, C. H.

Tunnell, $H . \wedge$.

Whitten, L. G., Jr
Wright, C. C.

$Y-12$ Central Files (master copy)

$Y-12$ Central Files (route copy)

$Y-12$ Central Files ( $Y-12 R C)$

$Y-12$ Central Files (5)

Paducah Gaseous Diffusion Plant

Bewley, H. D.

Sandia - Livermore

Spencer, W. J.

Union Carbide Corporation - New York

Tinsley, S. W.

In addition, this report is distributed in accordance with the Category UC-38, Engineering and Equipment, as given in the Standard Distribution for Unclassified Scientific and Technical Reports, DOE/TIC-4500. 